\title{
Arqueología, derechos humanos y política en Uruguay: una relación precaria
}

Arqueologia, direitos humanos e política no Uruguai: uma relação precária

Archeology, human rights and political in Uruguay: a precarious relationship

Jose Lopez Mazz

\section{Resumen}

La arqueología no deriva directamente en acciones y consecuencias políticas, nada más alejado de la excavación, y las sociedades pretéritas, que los escenarios políticos de confrontación, violaciones de los Derechos Humanos, propuestas de gobierno o cosas como la lucha de clases y la concentración de la riqueza; en el momento actual, su campo es el pasado. Pero esta condición de aparente desconexión del contexto, sin embargo, es la que facilita la relevancia política de la disciplina, la que paradójicamente adquiere su eficacia política, al presentarse como un recurso débil para esa acción. No obstante, la disciplina se ha visto envuelta históricamente en luchas ideológicas que arrastraron consecuencias políticas para la gente implicada. En ese sentido, puede ser peligroso seguir el sentido co- mún que pretende una arqueología sin virtudes políticas, que no puede accionar sobre el poder. Precisamente, trivializar esa relación es lo que permite a la política ingresar de un modo abierto y desembozado para llevar a cabo su agenda: politizar la disciplina, ignorando el contexto, al que precisamente la arqueología busca reaccionar y responder con herramientas propias.

Palabras clave: Arqueología. Derechos Humanos. Política. Uruguay.

\footnotetext{
Doutor em Arqueologia pela Université La Sorobona Paris III - IHEAL. Professor na Universidad de la República, Uuguai. Membro da Comisión Nacional del Patrimonio Cultural,Uruguai. Email: lopezmazz@yahoo.com.ar. Colaborou nesse artigo, Octavio Nadal, mestre em Ciências Antropológicas pela Universidad de La República, Uruguai. E-mail: octavionadal@gmail.com
}

Recebido em 05/10/2016 - Aprovado em 20/12/2016 http://dx.doi.org/10.5335/hdtv.17n.1.7235 
Political struggles over the past are first and foremost ideological, because their nature is usually hidden or obscured. Archaeology produces symbols, knowledge, and heritage, which give rise to awareness and consciousness of group identity and are invoked to inspire and justify collective agency. Randall McGuire (Archaeology as Political Action).

\section{Introducción}

Existe actualmente en nuestro medio una gran expectativa por la elaboración de una agenda común entre Arqueología y Derechos Humanos. Pero entre esta disciplina de vocación histórica y los escenarios recientes y contemporáneos de violaciones a los DDHH (Derechos Humanos), inevitablemente encontramos a la política. Hay un horizonte científico - crítico que se abre, buscando dar certezas, disminuyendo vaguedades e incertidumbres. En efecto, el escenario político precedente, acerca de este tema, estuvo signado únicamente por acuerdos políticos (cívico-militares y cívico-cívicos) sin bases concretas, más que los arreglos y compromisos que se permitían alcanzar. Se generó de ese modo un discurso cuya política de la verdad, se hallaba muy alejada de bases materiales, evidencias demostradas o concluyentes. Se desplegó en su lugar "declaraciones" puestas al servicio de intereses coyunturales, que no son ni verdaderas ni falsas, pues no esperan ser falseadas, solo tienen el valor de ajustar dentro de una cierta conformidad política, sin preocuparse de estándares y de reparar o esclarecer hechos.

El escenario de los DDHH, sin información útil para la búsqueda de cuerpos, recibió un tratamiento que no contemplaba la recuperación de los cuerpos. Se plasmó así una narrativa que usó los estereotipos de la "teoría de los dos demonios" (DEMASI, 2003) para dar sentido a la vieja agenda justificada través de dos plebiscitos (Art. $4^{\circ}$ de la ley de caducidad, que en medio de la impunidad que aseguraba a los perpetradores; habilitaba la investigación del destino de los Detenidos - Desaparecidos, cercenándose, sin embargo, la posibilidad de castigar los delitos cometidos por los perpetradores).

Los acuerdos políticos pretendían poner la racionalidad en la citada agenda, en especial la citada "teoría de los dos demonios", que desde 1983 había venido dando un sentido a las violaciones a los $\mathrm{DDHH}$ al imponer una lógica de enfrentamiento entre el "demonio militar" y el "demonio guerrillero" donde la población era víctima y espectador. En realidad lo que hizo esa teoría fue desplazar e invisibilizar el tema de los DDHH neutralizándolo como tópico y poniendo en su lugar un conflicto que se presentaba como absurdo. Por otro lado, "verdad y justicia" surgió como otro paradigma, que reclamaba por la responsabilidad, las complicidades y las omisiones del sistema en relación con la desaparición de personas durante la dictadura y la predictadura. Sin embargo, las apariencias indicaban que dos plebiscitos saldaban el asunto, (¿un error de la izquierda, un acierto para la derecha?). Pero la pregunta persistía y persiste: ¿Dónde están? ¿Qué pasó? con los “desaparecidos" durante la dictadura (1973 - 1985).

Veinte años de democracia en el año 2005, mostraban la impotencia del sistema político para dar respuestas, por los trillados carriles de los acuerdos y los discursos 
dirigidos a producir "verdades" a la medida de equilibrios y supuestas estabilidades que parecían nunca terminar de afianzarse. En ese momento, el trabajo de la arqueología se empezó a manejar como una vía posible de respuesta. Irónicamente, el Equipo Argentino de Antropología Forense (EAAF) estaba exhumando, desde 1984, los cuerpos de las víctimas de la dictadura argentina recién depuesta (SALADO; FONDEBRIDER, 2008). La labor forense del EAAF era una novedad en el escenario latinoamericano salido de las dictaduras, casi al fin de la Guerra Fría. En efecto, desde 1984 el trabajo del EAAF mostró al mundo a través de su tarea de exhumación y posterior identificación la evidencia indiscutible de los crímenes perpetrados por la dictadura en Argentina entre 1976 y 1983, sus métodos de producir la muerte y la desaparición de los militantes políticos y la oposición. Otros equipos similares se formaban en Perú, Chile, Guatemala, con distinto suceso. A partir de los años 90 se sumaría el también aterrador escenario de las fosas comunes de la guerra en la ex Yugoslavia, así como las masacres en Rwanda por el gobierno Hutu. El EAAF sería llamado a actuar en esos escenarios por su experiencia forense en búsqueda y recuperación de restos humanos en contextos de muertes producidas por los estados. También podríamos citar como antecedentes más remotos las masacres en Rusia y Polonia (aldea de Katyn) durante la II Guerra Mundial, que adquirieron un renovado valor a la luz de las masacres perpetradas por los dictadores latinoamericanos.

Un corte conceptual, un abismo casi, abrieron estos hechos ante disciplinas que como la arqueologia fueron tradicionalmen- te distinguidas por su discurso sobre los conflictos y contradicciones de a la sociedad actual. Como nunca, los tópicos de no neutralidad y de praxis mostraron necesidad de una arqueología científica cuya política es, rechazar todo acuerdo, todo compromiso que de antemano persiga un efecto. Analizar con recursos científico - técnicos para hacer más eficiente la búsqueda de los enterramientos clandestinos del régimen militar. Se procuró seguir estándares internacionales reconocidos por la ONU y otros Organismos internacionales. Pero era también la manifestación política de la necesidad de construir nuevas líneas maestras de racionalidad y sentido en una nueva agenda, que enfrentaba la imposibilidad de responder a las demandas de: ¿dónde están? Y ¿qué pasó? En efecto, hasta ese momento, como ya se dijo, la agenda se agotaba en acuerdos e instancias, petitorios, oficios, etc. pero no satisfacía, no conformaba, pues la desaparición de personas adquiría carácter permanente, en cuanto se constituía en un hecho presente, nunca resuelto, nunca finiquitado.

\section{La situación antes de 2005}

Los médicos forenses carecían de cuerpos para realizar pericias, los antropólogos forenses carecían de esqueletos para identificar. Un período se había cumplido, desde la salida de la dictadura, en que el pasado de los crímenes y las violaciones a los DDHH, las desapariciones, no tenían corpus. Un amplio espacio de desconocimiento recubría el pasado reciente, favoreciendo el negacionismo, sin más materialidad que las denuncias, sin restos, sin ruinas, sin escenarios de la 
muerte... entonces se llamó a los arqueólogos para iniciar la búsqueda.

Como sea que se haga, los arqueólogos siempre entran a desarrollar sus investigaciones en contextos políticamente condicionados, muchas veces rodeados de estereotipos que afectan la percepción de lo que la disciplina hace (MCGUIRE, 2008, p. 143). Para el caso uruguayo, la arqueología no jugó un papel decisivo en las luchas nacionales por el patrimonio y la identidad, como ocurrió en otros estados latinoamericanos, multiétnicos y que reivindican ese tipo de conflictos históricos. Sólo por citar un caso, el indigenismo, programa de políticas para los indígenas, que caracterizó uno de los lados de la lucha por la legitimidad de la ocupación de los territorios americanos, y en muchos procesos revolucionarios, por ejemplo México y Perú no tuvo expresión en Uruguay, no fue una herramienta que el estado utilizara (POLITIS, 1995, p. 201). Tal vez como resultado de un proceso de estabilización política, logrado a comienzos del siglo XX, una vez que se consolidó el sistema de partidos (RILLA, 2008, p. 122) con prácticas racionales y rituales civiles. En ese sentido, se cumplía con una aspiración de las elites, que venía desde los comienzos de la vida independiente, de segregar a los caudillos, y toda población subalterna, dejándolos fuera de la estructura partidaria, una vez inaugurada la vida independiente. Éstos jefes eran considerados una amenaza, por ser capaces de movilizar a las clases populares en clave de reclamos territoriales y patrios, contrarios a los intereses de comerciantes y propietarios urbanos, según resumiera Juan Pivel Devoto (RILLA, 2008, p. 123).
Probablemente sea este escenario el que favoreció la idea de una sociedad bárbara, asociada al pasado colonial (BARRÁN, 1977, p. 8) de la que había que desprenderse en pos del progreso. La historia partido-céntrica que sobrevendría luego, aplicaría esquemas europeos para entender los conflictos locales, produciendo así una historiografía historicista, que influenciaría las interpretaciones que la Sociedad de Amigos de la Arqueología dentro de los cánones de la escuela Histórico Cultural, que solo reconocía a los grupos indígenas registrados históricamente.

Este breve rodeo, es para circunscribir y ubicar a la arqueología uruguaya en el contexto de prácticas e ideas emanadas del proceso histórico, que desembocaría posteriormente en la dictadura que comenzó en 1973 hasta 1985.

La praxis política del estado entrará a partir de ese año de 1973 (BROQUETAS, 2014) en una dinámica de profundización de la aplicación de los métodos de represión, produciéndose sistemáticas "violaciones de los derechos humanos"; época que será caracterizada como de "terrorismo de estado" (MARCHESI; MARKARIAN, 2012, p. 214). Hasta ese momento, digamos que la historia había solventado el "mapeo" del pasado, constituyendo ella misma las herramientas válidas para entender y elaborar la memoria escrita de aquellos acontecimientos que le era dado relatar. Sin embargo, los sucesos que van a ocurrir a partir de esa fecha exigirán a las palabras, a los conceptos, una vez que la dictadura haya pasado, un ejercicio de representación sin igual, vale decir, la acción desmanteladora y terrorista tuvo 
una magnitud y calidad tal, que encogió los recursos disciplinarios clásicos de la historia para transmitir "lo que pasó". En toda historia hay narratividad sostiene Hayden White (1992) sino, no es posible urdirla, los hechos no "hablan solos". Seguramente fue esa -entre otras- una de las sorpresas y dificultades en los comienzos de la recuperación democrática en el año 1985, para que la vieja historia recomenzara, para que retomara el hilo de una racionalidad política agotada. Seguramente la consigna de "dar vuelta la página" del presidente Sanguinetti, escondía la esperanza del retorno al cauce conservador y arcádico de que en Uruguay "no pasa nada".

\section{Desaparición de personas, testimonios y objetos}

En realidad, la vuelta de la página, era un gesto disuasivo, una maniobra para ganar tiempo en reducir el pasado a la confrontación de los dos demonios y revivir el esquema de bandos, en una lógica sencilla de amigo enemigo. Sin embargo, el terrorismo de estado había afectado a la sociedad uruguaya, a través de prácticas autoritarias y represivas desplegadas de un modo técnico y sistemático, especializado y coordinado produciendo terror como era su objetivo, pero también resistencia y desobediencia (LÓPEZ MAZZ, 2006, p. 119). Las desapariciones forzadas, la tortura y la cárcel prolongada, la persecución política, y todo el escenario de violaciones graves a los $\mathrm{DDHH}$, que caracterizaron las dictaduras en el Cono Sur, en la década del 70, desbordaron los modos tradicionales de captar y transmitir lo ocurrido. Este sería, de un modo amplio, el contexto social que dejó el autoritarismo, de perplejidad y alteración dramática del statu quo.

\section{Una escritura arqueológica}

Resulta obvio que la arqueología no deriva directamente en acciones y consecuencias políticas, nada más alejado de la excavación, y las sociedades pretéritas, sus costumbres exóticas etc. que los escenarios políticos de confrontación, violaciones de los Derechos Humanos, propuestas de gobierno o cosas como la lucha de clases y la concentración de la riqueza; en el momento actual, su campo es el pasado... Pero esta condición de aparente desconexión del contexto, sin embargo, es la que facilita la relevancia política de la disciplina, la que paradójicamente adquiere su eficacia política, al presentarse como un recurso débil para la esa acción (MCGUIRE, 2008, p. 21). No obstante, la disciplina se ha visto envuelta históricamente en luchas ideológicas que arrastraron consecuencias políticas para la gente implicada. En ese sentido, puede ser peligroso seguir el sentido común que pretende una arqueología sin virtudes políticas, que no puede accionar sobre el poder. Ese camino ha mostrado, precisamente en Uruguay, como ha sido aprovechado para su utilización con fines políticos. Precisamente, trivializar esa relación es lo que permite a la política ingresar de un modo abierto y desembozado para llevar a cabo su agenda: politizar la disciplina, ignorando el contexto, al que precisamente la arqueología busca reaccionar y responder con herramientas propias. 
Se buscó así conducir su agenda académica a través de naturalizaciones, presuntamente surgidas de la objetividad de sus juicios. No tanto objetividad, sino un empirismo simple es el que invoca la política al referirse al carácter científico e imparcial de la práctica disciplinaria, como condición indispensable para alcanzar la objetividad y la verdad. En realidad, los avances en el terreno de la arqueología y los DDHH se han fortalecido a partir de hacer explícitas las responsabilidades políticas en juego, no refugiándonos en la objetividad o en el compromiso político con grupos u organizaciones. Hay todavía algo más, pues la arqueología no actúa en un terreno sin ideologías, si hay política hay ideología, hay propósitos políticos. Se debería conceder que puede haber la tentación de hacer algo "bueno para la sociedad", cuando inevitablemente sabemos que la labor arqueológica no puede satisfacer a todos por igual, ni dar la base para historias que integren y construyan muchas veces tienen el efecto contrario (MCGUIRE, 2008).

Nuestro contacto con la política es, como investigadores, para ver contradicciones, resistencias, pero también los errores que cometeremos como profesionales que buscan satisfacer las demandas sociales, en ese espacio participamos de la agenda política. Aquí es preciso marcar lo dicho más arriba acerca de la susceptibilidad política de la arqueología, señalar que la debilidad de la disciplina como herramienta política es parte de los modos de su utilización. Advertir que la labor disciplinaria siempre recibirá tensiones que desean torcerla en beneficio de intereses, levantando discursos acerca del compromiso político como gesto ennoblecedor. No podremos negar que el conocimiento que produce la arqueología es político, puede servir (y ha servido) para desafiar al statu quo (TRIGGER, 1992), y éste va a reaccionar muchas veces deslegitimando, resintiéndose de que "falta compromiso"; sugiriendo que en ese punto radica la "diferencia", ese suplemento, que siempre faltará, para alcanzar las certezas demandadas. Si bien la certeza y la verdad son una construcción, no significa que deriven directamente de su encuadre con las agendas políticas. Más bien éstas agendas están preocupadas por presentar su propia historia, su propia versión de "los hechos", no en contrastarla con otras alternativas, dejando el imprescindible espacio de incertidumbre que toda verdad científica debe tener.

Es este terreno el menos indicado para acreditar y abonar con hipótesis científicas, pues las complicidades y alianzas solamente pueden valer si se trivializa la relevancia política de la disciplina, para que sirva precisamente a fines políticos como ya se señalara.

\section{Arqueología Forense, definiciones, historia y contextos}

La Arqueología a la que nos referimos, ha sido definida como una disciplina forense que usa teoría arqueológica, métodos y técnicas en contextos legales (criminales, médico legales, humanitarios y relativos a la justicia civil) (GROEN et al., 2013). En palabra de uno de sus pioneros "El objeto de estudio de la escena del crimen es reconstruir un evento en el tiempo y sobretodo cuando la escena del crimen es una tumba clandes- 
tina" (SNOW, 2013, p. 31). Como afirmaba el Prof. Paul Courbin (1984), lo que sólo el arqueólogo hace es establecer hechos arqueológicos y en este contexto forense se ha tratado de buscar, ubicar e identificar la escena del crimen.

La arqueología forense aportó habilidades únicas y singulares a cada investigación; transformando la "prueba" en una historia coherente que nos cuenta de ¿cómo? fue cometido el crimen. Su metodología de trabajo asegura que toda la evidencia pertinente sea colectada y preservada. Aunque antropólogos forenses, expertos en DNA, patólogos u otros especialistas médico legales trabajan en buenas y equipados laboratorios no podrán resolver un caso sin la evidencia que aportan los arqueólogos forenses.

Desde 1943 que se hizo necesario investigar sobre las matanzas de Katyn (GROEN et al., 2013) la selección de conceptos, principios y procedimientos arqueológicos, se han instalado en el seno de disputas y conflictos sociales, dando lugar a experiencias singulares, que a su vez han permitido plantear interrogantes cada vez más precisas a los perpetradores de violencia y violaciones a los Derechos Humanos. El derecho internacional humanitario se hará cargo de escenarios históricos que dejan asuntos sin resolver, y demanda un control más eficiente y científico del vínculo entre conducta humana criminal y su producto material.

La emergencia de los equipos forenses marca, en la práctica, los avances y los desafíos disciplinarios, directamente influenciados por el trabajo en el terreno. A veces los arqueólogos forenses son llamados por los jueces, a veces por los familiares de las vícti- mas, a veces por organismos internacionales de DDHH y a veces por la sociedad civil organizada.

Los equipos tienen desde su nacimiento una marca que le impone una lectura, un punto de vista y un lugar en la escena histórica de las violaciones a los DDHH. Los equipos de voluntarios son luego substituidos por equipos profesionales, de las ONG's, estatales o internacionales, siempre en el marco de las fluctuaciones de lo que se dio en llamar "justicia transicional" (LESSA, 2014) de cada país. El pasado mueve y los muertos re-aparecen con inusitada vida política por lo cual, además del interés legal, son objeto de una gran disputa entre grupos que a veces articulan la preocupación pública con intereses sectarios.

La creación de la Comisión Internacional para Personas Desaparecidas para la ex Yugoslavia en 1996 (HANSON, 2013) constituyó un paso decisivo en la profesionalización de la búsqueda y localización de tumbas clandestinas. Un rol capital jugó el antropólogo y arqueólogo Richard Wright en el diseño, aplicación y evaluación de procedimientos en los trabajos de campo en Sebrenica, que buscaban llevar adelante las causas criminales al tiempo de localizar e identificar las tumbas clandestinas. La estrategia interdisciplinaria comenzó por articular los testimonios personales con la información producida por fotos aéreas, los relevamientos directos de terreno (superficiales y sub superficiales) y los muestreos. La excavación será la fase siguiente y de mayor esfuerzo, donde se producirá la información legalmente más contundente. Todo este proceso deberá contar con la asistencia de un es- 
pectro amplio de especialistas que analizan críticamente cada evidencia producida. El arqueólogo deberá asegurar la comprensión del proceso histórico de formación de la fosa, los contextos y asociaciones arqueológicas. Estos informes protocolizados fueron presentados y asumidos por la justicia internacional como "prueba" en relación a problemas y conductas precisas de los perpetradores. El análisis detallado de la secuencia estratigráfica del sitio resulta fundamental e ineludible, como eje de la argumentación.

La consolidación de una línea de trabajo en Arqueología y DDHH ha articulado avances producidos por equipos nacionales e internacionales. La experiencia generada por el Equipo Argentino de Antropología Forense ha tenido un efecto multiplicador en los cinco continentes. Esta práctica ha constituido un antecedente fundamental para los organismos internacionales, y ha marcado el desarrollo científico a través de una línea de trabajo con fuerte impronta latinoamericana (FONDEBRIDER; SCHAINSOHN, 2013).

En América Latina, los ciclos de violencia en Colombía, Perú, Argentina, Chile, Brasil y Uruguay; han dado lugar a un conjunto de experiencias concomitantes, que dinamizan los engranajes de la dialéctica social y suministran información de calidad para un análisis crítico. Violencias pre colombinas, conflictos coloniales y neocoloniales, genocidios étnicos, dictaduras militares, desarrollan un correlato criminal con una traza material que los arqueólogos se extreman en registrar. La experiencia latinoamericana es diversa en experiencias. En ese sentido, Baraibar y Mora (2013) ubican a la Arqueología Forense entre la ciencia y el activismo por los
Derechos Humanos, y señalan que ha sido fundamental la experiencia de campo de la arqueología prehistórica, y en el trabajo con restos humanos esqueletizados.

Es una constante en América Latina, que la habilitación de las investigaciones científicas sobre personas desaparecidas y asesinadas esté precedida por un escenario político (de transición a la democracia) que asegura amnistías e indultos para los perpetradores de los hechos criminales hasta entonces negados. En varios países aún, un entramado técnico legal defectuoso, sumado a disputas micropolíticas, están dilatando la enunciación de crímenes en masa de naturaleza política.

\section{Una relación entre política y ciencia}

La política "llama" a la ciencia, como ejercicio de honestidad pero también como forma de legitimarse en realidad, llama a los científicos en su calidad de integrantes de una comunidad, de una entidad que es política en la medida que es crítica, no porque esté más allá de consideraciones éticas o identificaciones ideológicas, sino porque cuestiona el esencialismo de posiciones que pretenden ser hegemónicas. Esta arqueología que se pretende desarrollar en el Uruguay, no desconoce los orígenes coloniales y nacionalistas que en el pasado la disciplina cultivó como hija de la modernidad (TRIGGER, 1992). Como pocas, se prestaba a la justificación del statu quo y visiones de progreso y pasados gloriosos, de ancestros heroicos conectados sutil y perspicazmente con gobernantes que buscaban mirarse en ese supuesto pasado célebre (KOHL et al., 2007). 
La transmutación crítica sufrida por la disciplina a partir de la II Guerra, rompió con ese paradigma, entre otras cosas porque aquel mundo se extinguió. Los escenarios se fragmentan, en un mundo también fragmentado, que más que continuidades y evolución cultural, muestra abismos y contradicciones, donde la condición de "primitivos" o "subdesarrollados" se asimila cada vez más a la de minorías explotadas, arrinconadas y despojadas (LÉVI-STRAUSS, 1995). En ese sentido, la "crítica" de la arqueología está justamente dirigida contra los relatos hegemónicos. La faena de la arqueología está dirigida más hacia la recuperación, hacia los olvidos, trayendo lo que nunca imaginamos, por esa razón, el negacionismo en arqueología, es el ejercicio contrario de la recuperación y del deseo de conocer lo que pasó.

Esta agenda nueva abre el juego no a la interpretación política en sí misma, sino que integra a la ciencia para mejorar la calidad de las herramientas, orientadas a resolver e identificar problemas forenses (legales) e históricos, que la política no había podido resolver desde su relato anterior a saber: dónde están y qué pasó? Es preciso indicar aquí que ya había habido, durante la dictadura, intervenciones periciales y técnicas, (autopsias practicadas sobre cuerpos de víctimas sin nombre - NN), que, sin embargo, no por expertas o especializadas, fueron menos funcionales al sistema que las requería.

En el período 1989 - 2005 la justicia estuvo inhibida de investigar, subsumiéndose el tema de los DDHH en la lógica de lo político, en el sentido de que "ya es un asunto laudado por el voto popular", ya está resuelto. Precisamente, los hechos arqueoló- gicos se constituyen con una independencia relativa de lo político, se juegan dentro del escenario político pero cuestionándolo, descentrándose de sus envites y mostrando las naturalizaciones que genera (MCGUIRE, 2008). Los Equipos de búsqueda no deberían realizan consultas más que técnicas, pues la delimitación precisa de los hechos científicos, debe evitar acreditarlos a través de discursos jurídico - políticos que acechan alrededor para construir otras lógicas, pretendiendo apoyarse en el discurso científico. La materialidad producida por la violencia construye una línea independiente de evidencias y resiste el manejo ideológico solamente si tiene un discurso que la sostenga como tal, que muestre la importancia política, las consecuencias de su manipulación. La verdad es siempre una propiedad del poder, el poder, sin verdad, no es poder, como decía Michel Foucault (1991), la ciencia en cambio debe construir condiciones, un terreno en el que la verdad sea algo en construcción, pero lo más alejada posible de hegemonías e intereses que la busquen como garantía.

En 2005 el presidente Tabaré Vázquez llama a la Universidad de La República (UDELAR) para que lo ayude en la tarea de buscar y devolver los huesos de los "Detenidos - Desaparecidos a los familiares de las víctimas". Un gesto que si bien cumplía con históricas demandas, no dejó por ello de sorprender a más de uno a la vez que creaba una gran expectativa, pues era un acto que interpelaba y desafiaba la lógica que durante 20 años de democracia, ley de impunidad de por medio, pretendía imponer una verdad: en Uruguay no hubo desaparecidos, a partir 
de admitir eso, se podía admitir cualquier cosa.

Fue una acción, la del presidente Vázquez, dirigida con neta precisión a recuperar la prueba, lo incontrovertible, lo hizo también con prescindencia de los perpetradores, de la temática de los juicios, no estaba dirigida contra nadie en particular. Se trataba de un ensayo de respuesta, un nuevo camino que apostaba a los estándares científicos, no al cálculo previo, sino a la experticia de una disciplina. Esta a su vez, al asumir la responsabilidad también reconoció que estaba frente a lo que diríamos un "giro" ya que contexto y período estudiado coincidían de modo atípico.

Todo lo realizado hasta ese momento podría ser contemplado como un trabajo de "rescate", por parte de la organización de Familiares y las ONG de DDHH. Un rescate de testimonios y referencias sobre el destino de los Detenidos - Desaparecidos. No es todavía un insumo que sirva si no está unido al rigor que requiere una investigación en marcha dirigida a aislar hechos, a construirlos de un modo crítico dentro de un plan y una estrategia, dirigidos por un objetivo: responder ¿dónde están? Y ¿qué pasó?

De este modo se construye, por un lado, un nuevo escenario de búsqueda con mayores probabilidades de hallazgo. $\mathrm{Y}$ se construye una nueva narrativa histórica que ahora habla de lo hasta entonces ignorado, pero con nueva base empírica. Por otro lado, se derivan hallazgos y pruebas hacia la justicia, elementos producidos por la observación controlada en escenarios de verificabilidad.
La eficacia y el poder simbólico de la búsqueda, son una herramienta fundamental de sensibilización social post dictadura, pero pueden ser una amenaza que vulnera los dispositivos de la ciencia, si son exitosamente cooptados por la política o por los poderes del Estado, caso de la SCJ con sus conflictos internos acerca de la interpretación de la ley de caducidad.

Con el paso de los gobiernos, con la evolución de los contextos políticos, la arqueología construyó su lugar, haciendo lo que sólo ella es capaz de hacer "estableciendo hechos arqueológicos" (COURBIN, 1984, p. 186). Pero la experiencia mostraba la fragilidad del accionar de los científicos en este tema, entre militares negacionistas, militantes ansiosos, periodistas pretenciosos y diversos actores políticos oportunistas.

En este complicado escenario, los arqueólogos, equidistantes de perpetradores, de instituciones estatales, de abogados, de familiares, de jueces y de testigos, han sentido que, siendo fiel a la ciencia, se puede ser más justo y comprometido. En este mapa local de la búsqueda de personas "Detenidas Desaparecidas" se ha levantado una sólida cartografía del horror con los hallazgos, yendo más allá de las construcciones sesgadas, de la demagogia, de las pequeñas disputas, de los protagonismos exagerados y de los vanguardismos políticos sectarios.

\section{¿Qué hace la arqueología?}

La arqueología es la historia de los que no tienen historia, es la manera de reconstruir los avatares de las sociedades que no fueron observadas. Se dirige a la "materiali- 
dad" que vincula la conducta humana con el mundo, es su punto de partida. Sin un objeto por delante no es posible adelantar ninguna interpretación. Se diría que la arqueología muestra, luego argumenta, luego interpreta.

La Arqueología entonces mostró, describió, explicó y demostró:

a) El ocultamiento sistemático de los cuerpos.

b) El uso de cal viva para destruirlos, y de cemento para impedir su recuperación.

c) El re poblamiento con especies forestales en los terrenos militares destinados a enterramientos clandestinos.

d) Detección de "claros" en la vegetación de los montes (de los predios militares) producidos por los perpetradores, que sirvieron de pista para los hallazgos.

e) La identificación y reconocimiento de elementos y rastros de tortura en los esqueletos.

f) Identificación de patrones de fractura en los restos óseos que posibilitan establecer causa de muerte.

g) Los objetos asociados, que acotan diacrónica y sincrónicamente el crimen.

h) Las regularidades y patrones en la escena de los crímenes, que muestra la coordinación represiva del Plan Cóndor.

Los dispositivos técnicos puestos a funcionar en el campo mostraron el carácter deliberado, indiscutiblemente intencional del ocultamiento y la negación de los crímenes. Pero además de la localización de los esqueletos, sobre todo se produjo información de calidad donde hasta entonces sólo había silencio. En efecto, las investigaciones arqueológicas desde 2005 en predios militares, ofrecieron evidencia no sólo de la contundencia de los hallazgos de los restos humanos posteriormente identificados como $\mathrm{DDHH}$, sino de diversas líneas de evidencia relacionadas con la investigación sobre la represión y el terrorismo de estado durante la dictadura. En ese sentido, la búsqueda del paradero de los restos humanos, permitió identificar indicios materiales en el terreno, que sirvieron de base para adelantar la hipótesis de la existencia de la llamada "operación zanahoria". Esta operación consistió en la remoción (por los perpetradores) de enterramientos clandestinos en Unidades Militares, donde habían ocultado los cuerpos de los asesinados, en puntos conocidos por ellos, descartando luego los restos en sitios secretos. La citada operación fue admitida por el General de la dictadura, Alberto Ballestrino, en un reportaje que le hiciera la Revista Posdata (Febrero de 1996) a través del senador Rafael Michelini. Una parte del delito es el ocultamiento, y el ejercicio de la arqueología es enunciarlo como una hipótesis.

La llamada "operación zanahoria" fue parte del ocultamiento; La Comisión para la Paz, creada por el presidente Jorge Batlle, en su Informe Final del año 2003, comunicó que los restos de los "Detenidos-Desaparecidos", muertos a partir de 1973, fueron exhumados a fines de 1984, incinerados y reducidos a cenizas, fueron arrojados al Rio de la Plata (PRESIDENCIA DE LA REPÚBLICA, 2006, p. 23). Las excavaciones arqueológicas del GIAF demostraron que esta versión no era necesariamente verdadera en toda su dimensión. En efecto, los estudios de fotointerpretación realizados sobre fotos aéreas 
de los terrenos militares, permitieron identificar modificaciones en la cubierta forestal efectuadas, por los militares: <http://sdh. gub.uy/inicio/institucional/equipos/equipo-de-antropologos/equipo-de-antropologos> (LÓPEZ MAZZ, 2005; 2011; 2012). Sin embargo, esos indicios de búsqueda, permitieron hallar enterramientos clandestinos primarios de personas Detenidas Desaparecidas durante la dictadura (LÓPEZ MAZZ, 2015, p. 91). La diferencia que la arqueología ofrece en este proceso de investigación es la de formular bajo la forma de hipótesis a contrastar, hechos, o sucesos, que de otro modo serían solo rumores o versiones periodísticas (NADAL, 2011, p. 118).

\section{Conclusiones}

Los hechos constituidos por la investigación arqueológica forense mejoraron la agenda de los DDHH a partir de un procedimiento independiente que se reporta a una materialidad indiscutible, con líneas definidas que se desmarcan del discurso político que busca rellenar lagunas en la historia.

Todo fue posible gracias a que se trató de una faena autónoma, que tuvo la precaución de mantenerse equidistante de la interpretación política y del juicio jurídico. El tiempo que pasó ha mostrado que el "compromiso político" en este tema se vuelve en contra de la agenda, no la deja avanzar. Tal vez pocas oportunidades muestran los inconvenientes y las contradicciones éticas en que se puede incurrir al poner la ciencia al servicio de la política.

La investigación desarrollada, apostó a la ciencia como opción política y no a la política como una opción científica. El científico tiene responsabilidad, hacia adentro y fuera de su comunidad, pero no se puede renunciar a la ciencia, no se puede manifestar abstención; se puede elegir "no elegir" si hay que optar entre dicotomías obligatorias que pretenden agotar toda realidad. No es solamente el caso de esta búsqueda; sino que este escenario de la arqueología siempre tienta a buscar una ciencia " $a d$ hoc" pues suele ser ésta la que siempre está como de medida para cumplir un objetivo político. En cuanto al compromiso-político como metáfora de una vía de superación política contra-hegemónica, este ha demostrado algunas limitaciones si no se adoptan modalidades de vigilancia, al menos sobre los núcleos de las disciplinas. Sin rechazar la política, creemos que un mayor compromiso político, no aumenta las probabilidades de hallazgo de los restos de los Detenidos Desaparecidos, y menos todavía, afina o sofistica los medios o amplía la capacidad de los investigadores. Es sólo demagogia oportunista.

El nacionalismo fue el discurso hegemónico del que históricamente la arqueología buscó desmarcarse, mostrando su sesgo y debilidad científica. Para el caso uruguayo, tal vez debamos ayudar a desmontar el mito de la resolución política y la vía del acuerdo para la construcción del relato histórico. La agenda nueva debe buscar poner luz sobre terrenos concretos, no sobre una superficie teórica modelada en consignas y declaraciones, no busca acuerdos. La historia es la hegemonía, la historia narrada, ese es el mito, que no acepta quiebres. La izquierda a veces no resiste la tentación de subirse a ese carro porque es seguro, y además seguro que te 
creen. Los arqueólogos deberían de preocuparse entonces de no ser funcionales a la política, sino más bien ser independientes, haciendo explícitas sus hipótesis y justificando claramente sus procedimientos. La situación política, el momento histórico, son el límite para lo que se puede pensar dentro de ese horizonte, como decía Gadamer (1984) son la posibilidad de la comprensión, una pretensión de verdad. La reflexión crítica es la salida, producir verdades, pero sin acuerdo previo, sino siempre gana la neutralidad y las apelaciones a la objetividad que el sistema de poder prodiga a las verdades que cobija.

Para terminar cabe subrayar que los 10 años de investigación arqueológica han mostrado un progresivo involucramiento y empoderamiento de la ciudadanía en el tema de la búsqueda de los desaparecidos. Este verdadero proceso de "patrimonialización" de los desaparecidos se opone firmemente a la disputa de facciones por el control político del tema, así como el pretendido monopolio y exclusividad que diferentes actores reclaman (algunos familiares, algunos periodistas, algunos académicos, algunos políticos) Los arqueólogos por su parte deberían -poniendo las barbas en remojo- hacer siempre explícita su actividad científica, como opción política y ética, a favor de determinadas causas. De ese modo no se dará lugar a que alguien piense que venden baldes de humo.

\section{Resumo}

A arqueologia não decorre diretamente de ações e consequências políticas; nada mais longe da atividade de escavação e das sociedades do passado do que os cenários políticos de confrontação, de violações dos Direitos Humanos, de propostas de governo ou de assuntos como a luta de classes e a concentração da riqueza. No momento atual, seu campo é o passado. Porém, essa condição de aparente desconexão é a que oportuniza a relevância política da disciplina, que demonstra paradoxalmente sua eficácia ao se apresentar como um recurso débil para essa ação. A disciplina, historicamente, tem estado envolta em lutas ideológicas que conduziram a implicações políticas as pessoas envolvidas. Nesse sentido, pode ser perigoso seguir o senso comum que objetiva uma arqueologia sem virtudes políticas, que não pode operar sobre o poder. Banalizar essa relação está permitindo que a política influa de forma aberta e sem disfarces na realização de sua agenda: politizar a disciplina, ignorando o contexto, situação a que, precisamente, a arqueologia busca reagir e responder com suas próprias ferramentas.

Palavras-chave: Arqueologia. Direitos humanos. Política. Uruguai.

\section{Abstract}

Archeology does not flow directly into political actions and consequences, nothing further from the excavation and societies from the past than the politi- 
cal scenarios of confrontation, human rights violations, government proposals or issues such as class struggle and concentration of wealth; In the present, them places is the past. However, this condition of apparent disconnection is what gives the political relevance of the discipline, which paradoxically acquires its effectiveness, presenting itself as a weak resource for this action. Discipline has historically been shrouded in ideological struggles that have led to political implications for the people involved. In this sense, it can be dangerous to follow the common sense that argues to an archeology without political virtues, that cannot operate on the power. To trivialize this relationship is allowing policy to openly and undisguisedly influence its agenda: to politicize discipline, ignoring the context, precisely which archeology seeks to react and respond with its own tools.

Keywords: Archeology. Human Rights. Politics. Uruguay.

\section{Nota}

Sociedad científica fundada en Montevideo en 1926, que reunía a intelectuales y políticos reconocidos en torno a temas especializados; arqueología, arte y arquitectura, con preferencia por el pasado indígena y colonial, con cierto tinte nacional.

\section{Referencias}

BARAIBAR, J. P.; MORA, F. Forensic Archaeology in Perú: between science and human right activism. In: GROEN, M.; MARQUEZGRANT, N.; JANWARY, C. Forensic Archaeology: a global perspective. Amsterdam: Wiley-Blackwell, 2013. p. 62-77.
BARRÁN, J. P. Apogeo y crisis del Uruguay pastoril caudillesco, 1839 - 1875. Montevideo: Ediciones de la Banda Oriental, 1977. Tomo 4.

BROQUETAS, M. La trama autoritaria: derechas y violencia en Uruguay (1958-1966). Montevideo: Ediciones de la Banda Oriental, 2014.

COURBIN, P. Qu'est ce que c'est que l'archéologie. Paris: Payot, 1984.

DEMASI, C. Un repaso a la teoría de los dos demonios. In: MARCHESI, A.; MARKARIAN, V.; YAFFE, J. A. (Comp.). El presente en dictadura. Montevideo: Trilce, 2003. p. 44-62.

FONDEBRIDER, L.; SCHAINSOHN, V. Forensic Archaeology: the Argenitina way. In: GROEN, M.; MARQUEZ-GRANT, N.; JANWARY, C. Forensic Archaeology: a global perspective. Amsterdam: Wiley-Blackwell, 2013. p. 369-378.

FOUCAULT, M. Microfísica del poder. Madrid: Ediciones de la Piqueta, 1991.

GADAMER, H. G. Verdad y Método. Salamanca: Editorial Sígueme, 1984. 3 vol.

GROEN, M.; MARQUEZ-GRANT, N.; JANWARY, C. Introduction. In: Forensic Archaeology: a global perspective. Amsterdam: Wiley-Blackwell, 2013. p. LI-LV.

HANSON, I. Forensic archaeogy and International Comission for Missing Person: settings standar and integrated process. In: GROEN, M.; MARQUEZ-GRANT N.; JANWARY, C. Forensic Archaeology: a global perspective. Amsterdam: Wiley-Blackwell, 2013. p. 415-426.

KOHL, P.; KOZELSKI, M.; BEN-YEHUDA, M. Introduction. In: _ (Ed.). Archaeology in the construction, commemoration and consecration of national pasts. Chicago: Univesity of Chicago Press, 2007. p. 24-32.

LÉVI-STRAUSS, C. Antropología Estructural. México: Siglo XXI, 1995.

LÓPEZ MAZZ, J. M. Una mirada arqueológica a la represión política en Uruguay (1971-1985). In: FUNARI, P. P.; ZARANKIN, A. (Org.). Ar- 
queología de la represión y la resistencia en América Latina en la era de las Dictaduras (décadas de 19601980). Buenos Aires: Secretaria de Derechos Humanos de la Nación, 2006. p. 66-88.

. The concealment of bodies during the military dictatorship in Uruguay (1973-84). In: ANSTETT, É.; DREYFUS. J. (Ed.). Human remains and identification: mass violence, genocide, and the "forensic turn". Manchester: Manchester University Press, 2015. p. 112-118. . Informe de actividades. 2005; 2011; 2012. Disponible en: <http://sdh.gub.uy/inicio/ institucional/equipos/equipo-de-antropologos/equipo-de-antropologos>. Acceso em: 11 sep. 2016.

MCGUIRE, R. Archaeology as political action. Berkeley: University of California Press, 2008.

NADAL, O. Arqueología y derechos humanos: otra legibilidad del pasado reciente en Uruguay. In: FRIED, G.; LESSA, F. (Org.). Luchas contra la impunidad (Uruguay, 1985-2011). Montevideo: Trilce, 2011. p. 27-35.

PRESIDENCIA DE LA REPÚBLICA. Investigación Arqueológica sobre Detenidos-Desaparecidos, en cumplimiento del Art. $4^{\circ}$ de la Ley 15.848. Montevideo: Dirección Nacional de Impresiones y Publicaciones Oficiales (IMPO), 2006. Tomo V. (Coordinación de J. M. López Mazz).

RILLA, J. La actualidad del pasado: usos de la historia en la política de partidos del Uruguay (1942 - 1972). Montevideo: Debate, 1988.

SALADO, M. Y.; FONDERBRIDER, L. El desarrollo de la Antropología Forense en la Argentina. Cuadernos de Medicina Forense, Barcelona, v. 14, p. 53-54, jul./oct. 2008.

SNOW, C. Foreword Archaeology. In: GROEN, M.; MARQUEZ-GRANT, N.; JANWARY, C. Forensic Archaeology: a global perspective. Amsterdam: Wiley-Blackwell, 2013. p. 27-34.
WHITE, H. Metahistoria: la imaginación histórica en la Europa del siglo XIX. Ciudad de México: FCE, 1992. 